\title{
Glutathione ethyl ester supplementation prevents airway hyper- responsiveness in mice
}

\author{
Qiaoyun Wang ${ }^{1 \#}$, Aimin $\mathrm{Li}^{2 \#}$, Yiqiong Zheng ${ }^{3}$, Shu Zhang ${ }^{1}$, Ping Wang ${ }^{1}$ \\ ${ }^{1}$ Department of Respiratory and Critical Care Medicine, the Eighth Medical Center of PLA General Hospital, Beijing, China; ${ }^{2}$ Department of \\ Respiratory and Critical Care Medicine, First Hospital of Shanxi Medical University, Taiyuan, Shanxi province, China; ${ }^{3}$ PLA General Hospital, \\ Beijing, China \\ Contributions: (I) Conception and design: S Zhang; P Wang; (II) Administrative support: S Zhang; (III) Provision of study materials or patients: \\ Q Wang, A Li, Y Zheng; (IV) Collection and assembly of data: S Zhang; (V) Data analysis and interpretation: P Wang; (VI) Manuscript writing: All \\ authors; (VII) Final approval of manuscript: All authors. \\ \#These authors contributed equally to this work. \\ Correspondence to: Shu Zhang; Ping Wang. Department of Respiratory and Critical Care Medicine, the PLA General Hospital, Beijing, China. \\ Email: zhangshuxxx@163.com; taoybs_wp@163.com.
}

Background: Oxidative stress plays an important role in the pathogenesis of asthma. Glutathione (GSH) is considered to be one of the most important antioxidants. Our study systematically investigated the effect of the GSH alternative, glutathione ethyl ester (GSH-EE), on airway hyper-responsiveness (AHR) in mice.

Methods: Sixty-three male specific pathogen-free mice were used. Asthma was induced using a single dose of ovalbumin (OVA). The normal group $(\mathrm{n}=15)$ received vehicle only $[\mathrm{Al}(\mathrm{OH}) 3$ in saline]. Then, 48 mice were divided into two groups, including a control group who received sodium phosphate buffer ( $\mathrm{pH}=7.4$ ), and the GSH-EE group who received 0.1\% GSH-EE. AHR was measured 2, 6, and 12 hours after exposure to nebulized OVA $(0.01 \%)$. The animals were then sacrificed, and lung tissue and the bronchi-alveolar lavage fluid (BALF) were harvested. Factors involved in the antioxidant response to asthma were then measured in these tissues, including thiol content (from GSH and protein), $\gamma$-glutamylcysteine synthetase ( $\gamma$-GCS) activity and expression, and nuclear factor-erythroid-2-related factor (Nrf2) expression.

Results: The GSH-EE group showed a significant attenuation of AHR $(\mathrm{P}<0.01) 2$ hours after OVA challenge, and significantly enhanced thiol contents by approximately $45 \%(\mathrm{P}<0.05)$ at 2 and 6 hours after the last OVA challenge, compared to the control group. $\gamma$-GCS activity was also higher in the GSH-EE group compared to the control group at different time points $(\mathrm{P}<0.01)$. $\gamma$-GCSh and Nrf2 protein expression increased in the GSH-EE group and the control group compared with the normal group, but there was no statistically significant difference $(\mathrm{P}>0.05)$ between the GSH-EE group and the control group.

Conclusions: GSH-EE supplementation can prevent AHR in asthmatic mice during the early stages. It may function by serving as a precursor for GSH biosynthesis and by protecting sulfhydryl groups from oxidation.

Keywords: Glutathione ethyl ester (GSH-EE); glutathione (GSH); ovalbumin (OVA); $\gamma$-glutamylcysteine synthetase $(\gamma$-GCS); nuclear-factor-erythroid-2-related factor (Nrf-2); airway hyper-responsiveness (AHR)

Submitted Sep 23, 2020. Accepted for publication Nov 13, 2020.

doi: $10.21037 / \mathrm{atm}-20-7114$

View this article at: http://dx.doi.org/10.21037/atm-20-7114 


\section{Introduction}

Understanding the mechanisms underlying the development of asthma and finding effective therapeutic strategies are problems of great scientific and social interest. It has been reported that over 300 million people worldwide suffer from asthma across both adults and children $(1,2)$. Asthma is a chronic inflammatory disorder of the airways associated with airway hyper-responsiveness (AHR) and airflow limitation in response to specific triggers. Oxidative stress plays an important role in the pathogenesis of asthma (1,3-5), promoting inflammation and shifting redox balance towards oxidation reactions (6-8).

Glutathione (GSH) is an antioxidant that was first recognized in the 1970s, and is considered to be one of the most important antioxidants (1). Early studies reported that it was significantly decreased in asthma patients compared to healthy controls (9). In early asthma and AHR animal models, the tissue contents of GSH were shown to decrease (10). It was also found that GSH can decrease bronchial smooth muscle contraction, which was induced by oxidant free radicals in response to different stimuli (11).

Since GSH has a short half-life, resulting in limited cellular uptake, several alternatives to increase intracellular levels of GSH have been developed (12-15). Glutathione ethyl ester (GSH-EE) is one of these GSH alternatives, and has been shown to boost thiol content in cells through hydrolysis to release GSH $(16,17)$. GSH-EE injected intraperitoneally in mice was able to effectively decrease ovalbumin (OVA)-induced inflammatory cell infiltration and cytokine synthesis (10). GSH and GSH-EE atomization and intravenous injection have also been reported to relieve AHR and airflow limitation in response to early asthma $(8,18)$. Furthermore, it has been reported that GSH and GSH-EE can decrease airway responsiveness (AR) by directly relaxing bronchial smooth muscle contractions $(8,11)$. However, these previous studies did not perform a systematic investigation from in vitro to in vivo, and did not examine the antioxidant regulatory enzymes that are important in asthmatic pathologic processes.

To follow up on these findings, we systematically investigated how early asthmatic reactions induced by an allergen (OVA-induced asthma model) modulated antioxidant levels in vivo and in vitro, and tested whether supplementation with GSH-EE can prevent AHR and increase GSH content. We also investigated the response of GSH regulatory enzymes, including $\gamma$-glutamylcysteine synthetase $(\gamma-\mathrm{GCS})$, the rate-limiting enzyme of GSH, and nuclear-factor-erythroid-2-related factor (Nrf-2), which plays an important role in regulating the expression of intracellular $\gamma$-GCS $(19,20)$.

We present the following article in accordance with the ARRIVE reporting checklist (available at http://dx.doi. org/10.21037/atm-20-7114).

\section{Methods}

\section{Materials}

OVA and GSH-EE were purchased from Sigma Chemical Company (Beijing, China). BALB/c mice were provided by Animal Laboratories of Chinese PLA general hospital (Beijing, China). Protein and enzyme quantification kits were obtained from Jiancheng Biology Company (Nanjing, China). All other chemicals and instruments were obtained from local companies.

\section{Animals}

The experiments lasting over 3 weeks were performed using 2-month-old male specific pathogen-free mice $(n=63)$, which were housed in individual polypropylene breeding cages under a day/night cycle of 12 hours at $20-25^{\circ} \mathrm{C}$ room temperature, and provided with food and water ad libitum. Animal care and protocols were in accordance with the guidelines for animal care and approved by the Institutional Animals Ethics Committee at the Chinese People's Liberation Army General Hospital.

\section{OVA sensitization and challenge (8)}

All animals weighing 20-25 g were sensitized by injecting a mixture of $20 \mu \mathrm{g}$ OVA and $2 \mathrm{mg}$ of adjuvant $\mathrm{Al}(\mathrm{OH})_{3}$ in $1.0 \mathrm{~mL}$ saline. All animals were randomly assigned to each experimental group. $\mathrm{Al}(\mathrm{OH})_{3}$ in saline was administered to the normal controls $(\mathrm{n}=15)$. Each animal was injected intraperitoneally on days 0 and 14 , and repeated airway challenges with aerosolized 1\% OVA in PBS (30 min) on days 28,29 , and 30 were performed as described previously $(21,22)$.

\section{GSH-EE supplementation}

Five $\mathrm{mg}$ of GSH-EE was dissolved in $5 \mathrm{~mL}$ of sodium phosphate buffer solution ( $\mathrm{pH}$ 7.4). The $\mathrm{pH}$ value of the GSH-EE solution was adjusted to 7.2 before use. The GSH-EE group ( $\mathrm{n}=24)$ was treated with $0.1 \mathrm{~mL}$ GSHEE injected intraperitoneally once daily during the 
3 days before OVA challenge. Sodium phosphate buffer solution was used as the drug vehicle control $(n=24)$. GSHEE was tested for drug safety and utility by preliminary experiments. There was no statistically significant difference between drug-treated mice and untreated mice when observed for irritation or abdominal symptoms. The GSHEE solutions were made fresh daily and preserved in a $4{ }^{\circ} \mathrm{C}$ icebox. During injection, the rats were held by assistants, and continuously held for a 2-3 minutes light massage of the injection site.

\section{Measurement of airway responsiveness}

Two, six, and twelve hours after mice were exposed to nebulized OVA (0.01\% in saline), AHR was measured in unrestrained mice by using barometric whole-body plethysmography (WBP), as previously described $(18,21,23)$. Each mouse was placed in a main plexiglas Buxco chamber of the body plethysmograph, exposed to increasing concentrations of nebulized methacholine $(\mathrm{MCh})$ from $0-50 \mathrm{mg} / \mathrm{mL}$ to establish a dose-response relationship for 2 minutes, followed by a 3-minute period during which airway responses (enhanced pause, Penh values) were recorded. Penh values that were twice the baseline levels were recorded as PC100, $\log _{2}(10 \mathrm{PC} 100)$ and was statistically analyzed for airway responses. As an index of in vivo airway obstruction, AHR was calculated from 3 separate experiments (21-24).

\section{Bronchi-alveolar lavage fluid (BALF) analysis}

Following euthanasia of mice (pentobartone sodium, $0.6 \mathrm{~g} / \mathrm{kg}$ body weight, intraperitoneally), the lungs were lavaged with $500 \mu \mathrm{L}$ of sterile saline through a cannula in the trachea at $32{ }^{\circ} \mathrm{C}$, and withdrawn after 10 seconds. This procedure was repeated twice. The BALF was centrifuged at $1,500 \mathrm{rpm}$ for 5 minutes at $4{ }^{\circ} \mathrm{C}$, and the supernatant was retained for measurements of GSH/GSSG levels and protein levels. Once the supernatant was removed, the cell pellets were pooled for differential cell counts using $100 \mu \mathrm{L}$ of the re-suspended cells.

\section{Thiol determination in lung tissue and BALF $(18,24,25)$}

Thiol levels from GSH and protein were determined using the dithiobis-nitrobenzoic acid (DTNB) recycling assay measured by absorption at $412 \mathrm{~nm}$. Values were expressed as nmol per mg tissue protein (wet weight) for lungs, and $\mu \mathrm{M}$ for BALF.

\section{y-GCS activity assay in lung tissue}

Using the classic dual enzymatic method (26), absorbance was measured at $340 \mathrm{~nm}$ in $1 \mathrm{~mL}$ total volume of reaction solution, and $\gamma$-GCS activity was defined as $(\mathrm{U})$ $=1 \mathrm{nmol} / \mathrm{min} / \mathrm{mg}$ protein.

\section{Reverse transcription and real-time PCR}

To measure $\gamma$-GCSh ( $\gamma$-GCS synthetase heavy subunit) mRNA and Nrf2 mRNA levels in lung tissue, total RNA was isolated from the right lung, and reversetranscribed into cDNA. Real-time PCR was performed using the SYBR Green Realtime PCR Master Mix (TOYOBO, Osaka, Japan). GAPDH mRNA was used as an internal standard. The primers used in this study were as follows: $\gamma$-GCSh mRNA, the forward primer was 5'-AAGCTCTTGCCGAAAACCCA-3', and the reverse primer was 5'-GGAGCACGTCACATCCAGTT-3'. Nrf 2 mRN, the forward primer was 5'-GGACATGGAGCAAGTTTGGC-3', and the reverse primer was 5'-CCAGCGAGGAGATCGATGAG-3'.

\section{Western blot}

To measure $\gamma$-GCSh and Nrf2 protein expression, lung lysates were mixed with NuPAGE LDS sample buffer (4x), boiled, and loaded onto NuPAGE Bis-Tris Mini Gels. Proteins were transferred to nitrocellulose, and immunodetection for $\gamma$-GCSh protein and $\mathrm{Nrf2}$ protein was performed using anti- $\gamma$-GCSh antibody (S-16, Santa Cruz) and anti-Nrf2 primary antibodies (C-20, Santa Cruz).

\section{Statistical analysis}

Data are expressed as mean \pm SEM. One-way ANOVA was used for testing statistical significance between groups. $\mathrm{P}<0.05$ was considered statistically significant. All statistical analysis was performed using the SPSS statistical package version 21.0 (SPSS Inc., Chicago, USA).

\section{Results}

\section{Effect of GSH-EE on AHR}

The GSH-EE group $(\mathrm{n}=24)$ was treated with GSH-EE 

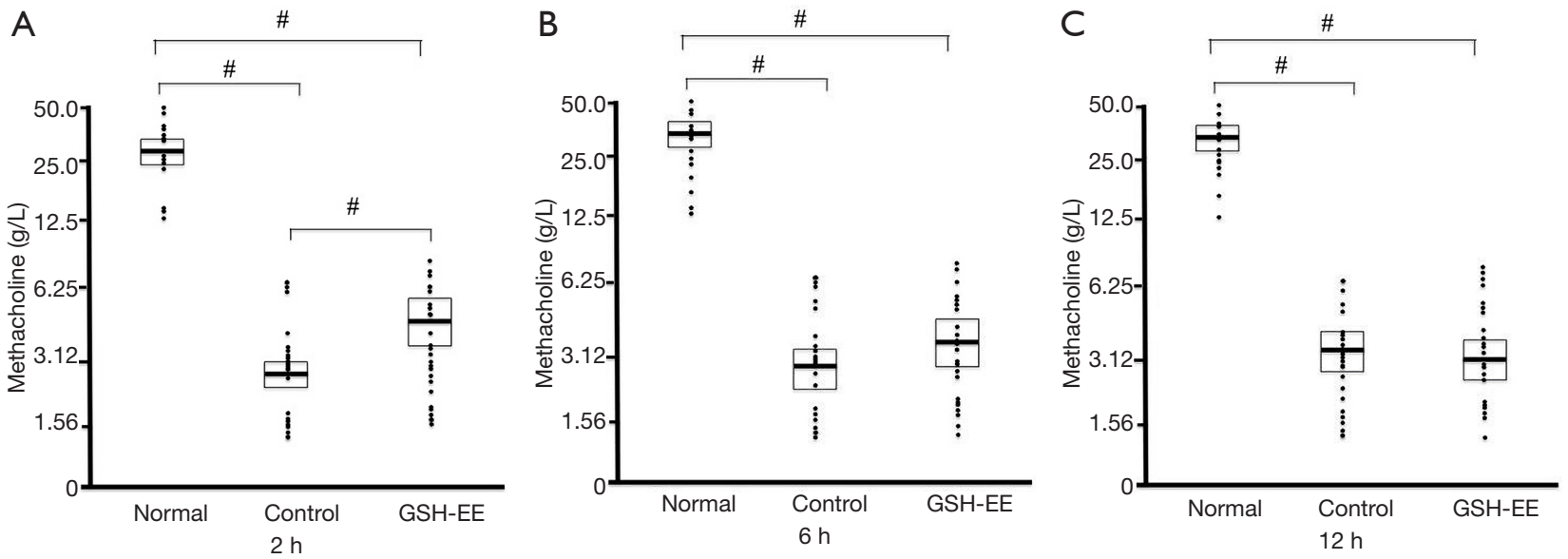

Figure 1 Comparison between airway hyper-responsiveness (AHR) in mice at different time points post-ovalbumin (OVA) challenge. Dots on figures represent the dose of methacholine (Mch) causing 100\% increase in airway resistance from baseline levels (PC100). (A) 2 hours (h), (B) 6 hours, and (C) 12 hours after the last challenge with OVA, the AR was recorded. OVA-induced asthmatic mice [control group $\mathrm{n}=24$; glutathione ethyl ester (GSH-EE) group, $\mathrm{n}=24$ ] showed significantly higher $\mathrm{AR}\left({ }^{*}, \mathrm{P}<0.01\right.$ ) compared to normal control mice (normal group, $\mathrm{n}=15$ ). (A) The GSH-EE group showed significantly decreased AHR (, $\mathrm{P}<0.01$ ) compared to the control group 2 hours after OVA challenge. (B,C) However, there were no obvious differences between the two groups 6 and 12 hours after OVA-challenge. ${ }^{\#}$ represents a significant difference compared to controls (", $\mathrm{P}<0.01)$.
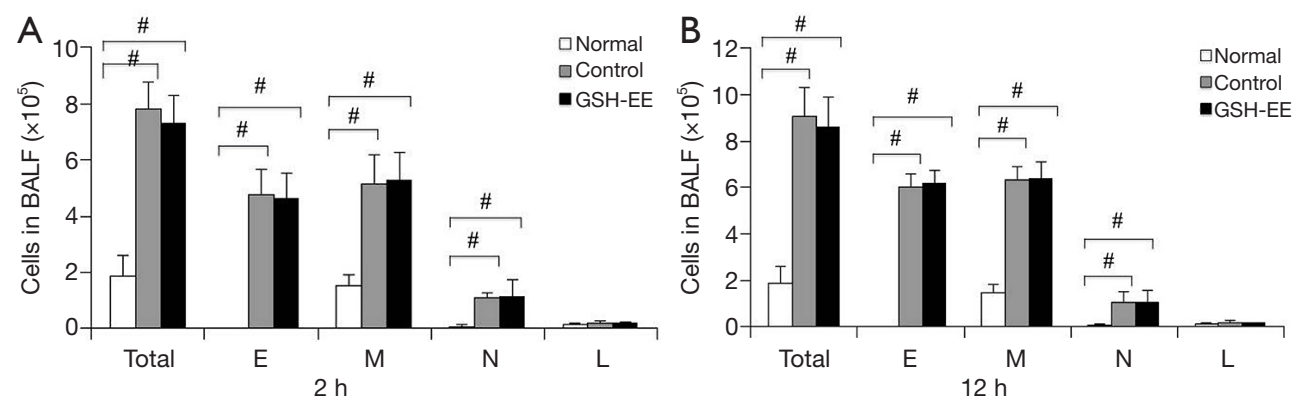

Figure 2 Inflammatory cells counts in bronchi-alveolar lavage fluid (BALF). Bars above represent cells counts at different time points after the last challenge with ovalbumin (OVA), ${ }^{*}$ represents a significant difference compared to controls (", $\left.\mathrm{P}<0.01\right)$. (A) 2 hours and (B) 12 hours after the last challenge, OVA-induced asthmatic mice (grey bars, control group; black bars, glutathione ethyl ester (GSH-EE) group) showed significantly increased numbers of inflammatory cells in BALF compared to the normal group (white bars; $\mathrm{P}<0.01$ ). No significant difference was found between the control group and the GSH-EE group. Total, total number of cells; E, eosinophils; M, monocytes; L, lymphocytes; N, neutrophils (the bar indicates mean \pm SEM, $n=8$ for control group and GSH-EE group, $n=5$ for normal group).

daily before the first OVA challenge, while the control group was treated with sodium phosphate buffer $(n=24)$ daily. AHR was measured at 3 different time points (2, 6, 12 hours) after the last OVA challenge. OVA-induced asthmatic mice (control group and GSH-EE group) showed significantly higher AHR $(\mathrm{P}<0.01)$ compared to normal control mice (normal group $\mathrm{n}=15$ ) across the entire observation period (Figure 1A,B,C). GSH-EE treated mice showed a significantly greater ability to attenuate AHR
$(\mathrm{P}<0.01)$ compared to vehicle treated mice 2 hours after OVA-challenge (Figure 1A), while no obvious differences were found between the two groups at 6 and 12 hours after OVA-challenge.

\section{Analysis of inflammatory cells in BALF}

OVA-induced asthmatic mice had significantly increased inflammatory cell counts $(\mathrm{P}<0.01$, Figure $2 A, B)$, especially 

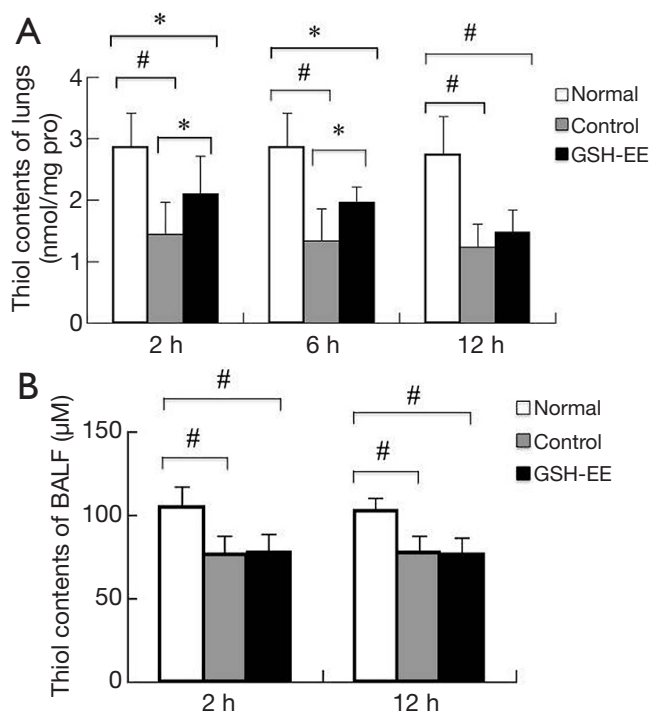

Figure 3 Thiol levels in lung tissue and bronchi-alveolar lavage fluid (BALF) of mice. Bars above represent the level of thiols from GSH and protein at different time points after the last challenge with ovalbumin (OVA), \#,* represent significant differences compared to controls ( $\left.{ }^{\#}, \mathrm{P}<0.01 ;{ }^{*}, \mathrm{P}<0.05\right)$. Asthmatic mice (control group and glutathione ethyl ester (GSH-EE) group) showed significantly lower levels of thiols than the normal group at different time points. (A) The GSH-EE group showed higher levels of thiols in lung tissue compared to the control group at 2 and 6 hours after the last OVA challenge. (B) No significant differences were found between the GSH-EE group and the control group in BALF (the bar indicates mean \pm SEM, $n=8$ for control group and GSH-EE group, n=5 for normal group).

eosinophil (E), monocyte (M), and neutrophil (N) cell counts, compared to normal mice. The GSH-EE group showed no significant change in total and differential cell counts compared with the control groups at different time points (Figure 2A,B).

\section{Thiol levels (from GSH and protein)}

After the last challenge, OVA-induced asthmatic lungs demonstrated a $25-55 \%$ decrease in the level of thiol contents in lung tissue $(\mathrm{P}<0.01)$ and a $20-30 \%$ decrease in the level of thiol contents in BALF $(\mathrm{P}<0.01)$ compared to control mice at each time point (Figure $3 A, B$ ). However, these differences were not time-dependent. Thiol levels were lower in BALF fluid compared to lung tissue. Surprisingly, GSH-EE significantly enhanced thiol levels by approximately $45 \%(\mathrm{P}<0.05)$ compared to the control group

\section{Discussion}

GSH is the abundant intracellular antioxidant thiol and plays an important role to redox defense during oxidative stress. This study showed that thiol content (GSH and protein) was markedly depleted in an experimental asthma model. Our data showed that thiol levels in lung tissue decreased during the early stages of experimental AHR with supplementation of an GSH donor, GSH-EE. The acute thiol depletion and bronchoconstriction that accompanied the allergic reaction are probably causally related, since supplementation with GSH-EE prevented AHR during the early stages of experimental AHR.

The occurrence of oxidative stress during primary AHR is interesting, since inflammatory cells have not yet been recruited to the lungs as a result of prior respiratory allergen challenge $(27,28)$. Repeated OVA challenge consistently 

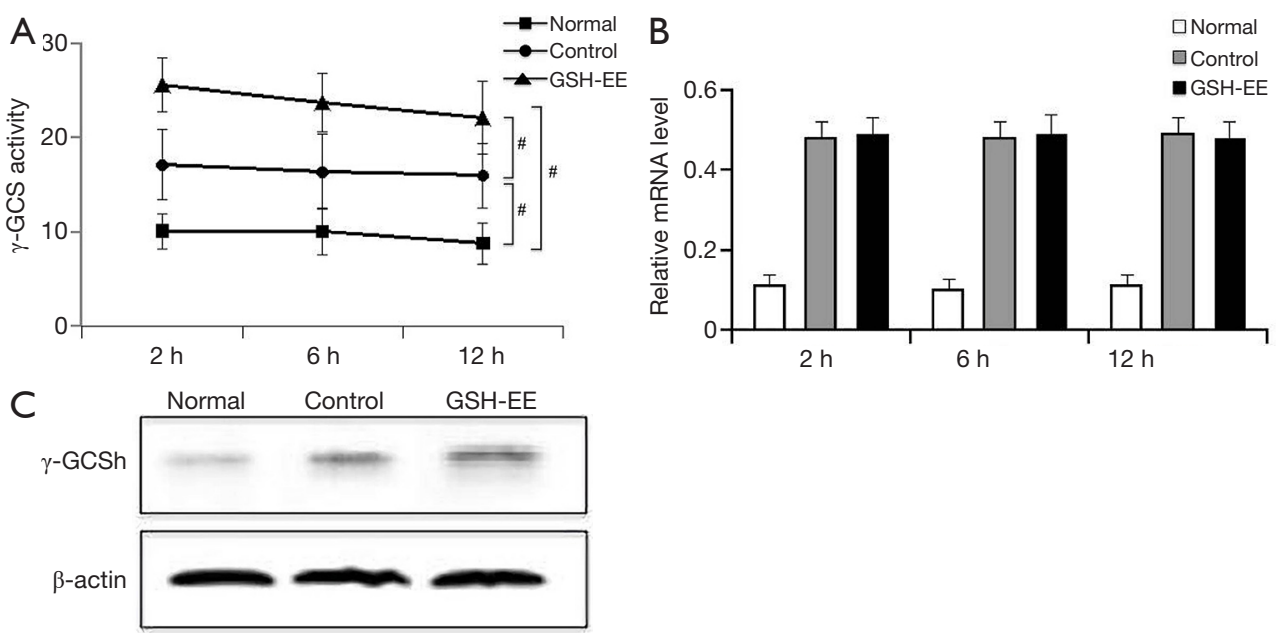

Figure $4 \gamma$-GCS activity, $\gamma$-GCSh mRNA, and $\gamma$-GCSh protein expression in lung tissue. (A) The curve represents the level of $\gamma$-GCS activity at different time points after the last challenge with ovalbumin (OVA), " represent significant differences compared to controls (\#, $\mathrm{P}<0.01)$. The control group and the glutathione ethyl ester (GSH-EE) group showed higher levels of activity compared to the normal group at different time points $(\mathrm{P}<0.01)$. The GSH-EE group showed higher levels of $\gamma$-GCS activity compared with the control group at 2,6 , and 12 hours after the last OVA challenge $(\mathrm{P}<0.01)$. (B) Results of RT-PCR showed higher levels of relative $\gamma$-GCSh mRNA expression in the control group and the GSH-EE group compared to the normal group at different time points $(\mathrm{P}<0.01)$, though there was no significant difference between the GSH-EE group and the control group. (C) Western blotting demonstrated consistent results, with a higher level of $\gamma$ GCSh protein expression in the GSH-EE group and the control group, though there was no significant difference between the GSH-EE group and the control group (the bar and dots indicate mean \pm SEM, $n=8$ for control group and GSH-EE group, $\mathrm{n}=5$ for normal group).
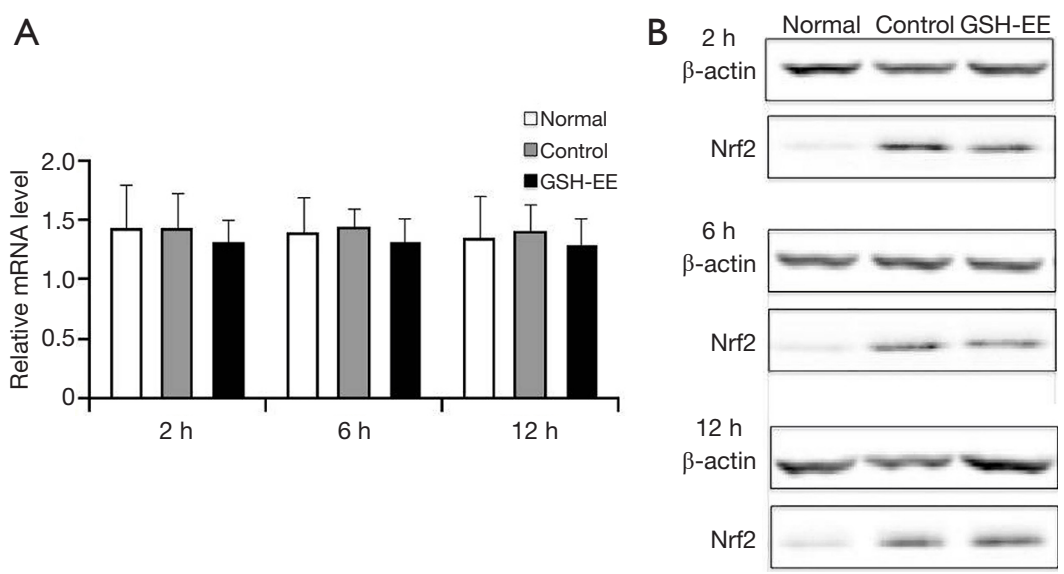

Figure $5 \mathrm{Nrf} 2 \mathrm{mRNA}$ and Nrf2 protein expression in lung tissue. (A) Results of RT-PCR showed no significant differences in relative expression levels of Nrf2 mRNA between the three groups at different time points. (B) Western blot demonstrated a higher level of Nrf2 protein expression in the glutathione ethyl ester (GSH-EE) group and the control group compared to the normal group at different time points, though there was no significant difference between the GSH-EE group and the control group at 2, 6, and 12 hours after the last ovalbumin (OVA) challenge (the bar indicated mean \pm SEM, $n=8$ for control group and GSH-EE group, $n=5$ for normal group). 


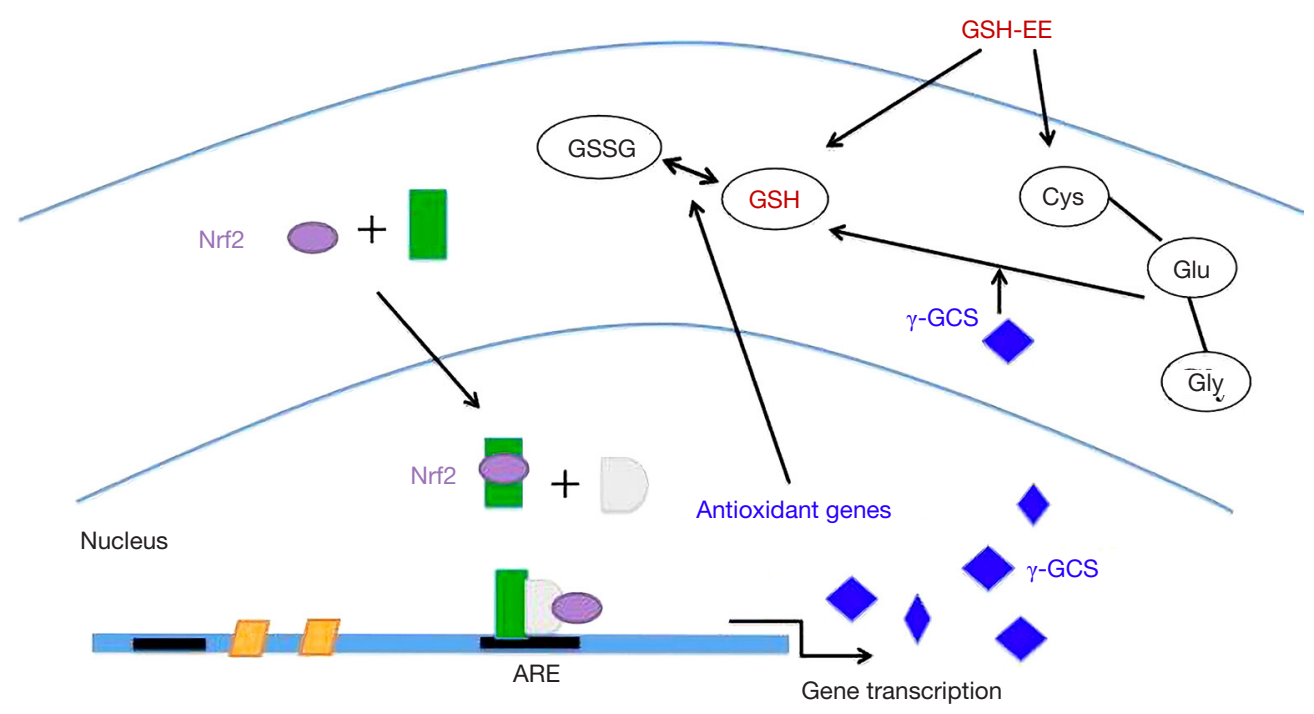

Figure 6 Schematic diagram illustrating the proposed mechanisms of glutathione (GSH) synthesis by glutathione ethyl ester (GSH-EE) supplementation. GSH-EE is one of the GSH alternatives, and has easier cellular uptake. It undergoes hydrolysis to form GSH, and partly boosts cysteine (Cys) levels. $\gamma$-GCS catalyzes the rate-limiting reaction in GSH biosynthesis. Transcriptional activation of antioxidant defense genes through antioxidant response elements (ARE) is dependent on nuclear factor-erythroid-2-related factor (Nrf2), a member of the Cap'n'Collar (CNC) family of basic ZIP transcription factors. A number of GSH regulatory enzymes are induced by Nrf2, as it translocates to the nucleus and binds with AREs which are located in the promoter region of many antioxidant genes, including $\gamma$-GCS.

increased BALF cell counts in the sensitized animals. Although this inflammatory cell influx has been related to oxidative stress, supplementation with GSH-EE around the time of each OVA challenge did not change BALF cell numbers in our experiment. These findings showed that GSH-EE supplementation had no obvious effect on alleviating inflammatory cell infiltration, though they are in accordance with previous research demonstrating that GSH and GSH-EE decrease AHR by directly relaxing bronchial smooth muscle contraction $(8,11)$.

Although the source of the oxidative burst is unknown, changes in the contents of antioxidant thiols can affect signaling pathways that participate in a broad range of physiological responses $(1,29)$. The early loss of thiol levels in asthma may result from the inactivation of various enzymes including $\gamma$-GCS, which plays a key role in maintaining GSH levels $(29,30)$. Our data suggests that the beneficial effects of GSH-EE supplementation were associated with $\gamma$-GCS activity improvement, while no effects accompanied $\gamma$-GCSh mRNA and protein expression.

Nrf2 has been demonstrated to regulate both the basal and inducible expression of many antioxidant response element (ARE) genes and the induction of the $\gamma$-GCSh gene
(30-34). The data showed Nrf2 protein expression increased in asthmatic mice, although GSH-EE supplementation had no effect on altering Nrf2 mRNA levels and protein expression in our experiments. In previous studies, $\mathrm{Nrf} 2$ has been shown to play a central role in controlling the redox equilibrium of dendritic cells, thereby influencing antigen presentation activity (35). These studies warrant investigation of $\mathrm{Nrf} 2$ activity in patients with asthma, which may aid in providing a novel therapeutic target.

In conclusion, this study showed that GSH-EE supplementation delayed the progression of early asthmatic reactions and AHR in mice. GSH-EE serves as a precursor for GSH biosynthesis, thereby increasing the levels of thiols in lungs, and inhibiting oxidative insults. Although GSH-EE supplementation had no obvious effects on GSH regulatory enzymes including $\gamma$-GCS which was induced by $\mathrm{Nrf} 2$, these interesting results may still lead to a novel therapeutic target with further research (Figure 6). Therefore, understanding the regulatory mechanisms for the induction of antioxidants, such as GSH, versus proinflammatory mediators at sites of oxidative-directed injuries may facilitate the development of novel therapies that will allow for pharmacological manipulation of GSH synthesis during inflammation and oxidative injury in 
asthma.

\section{Acknowledgments}

Funding: This work was supported by the Chinese PLA General Hospital Science and Research fund (2013FCTSYS-3005) and WU JIEPING Medical Foundation.

\section{Footnote}

Reporting Checklist: The authors have completed the ARRIVE reporting checklist. Available at http://dx.doi. org/10.21037/atm-20-7114

Data Sharing Statement: Available at http://dx.doi. org/10.21037/atm-20-7114

Conflicts of Interest: All authors have completed the ICMJE uniform disclosure form (available at http://dx.doi. org/10.21037/atm-20-7114). The authors have no conflicts of interest to declare.

Ethical Statement: The authors are accountable for all aspects of the work in ensuring that questions related to the accuracy or integrity of any part of the work are appropriately investigated and resolved. Animal care and protocols were in accordance with the guidelines for animal care and approved by the Institutional Animals Ethics Committee at the Chinese People's Liberation Army General Hospital.

Open Access Statement: This is an Open Access article distributed in accordance with the Creative Commons Attribution-NonCommercial-NoDerivs 4.0 International License (CC BY-NC-ND 4.0), which permits the noncommercial replication and distribution of the article with the strict proviso that no changes or edits are made and the original work is properly cited (including links to both the formal publication through the relevant DOI and the license). See: https://creativecommons.org/licenses/by-nc-nd/4.0/.

\section{References}

1. Fitzpatrick AM, Jones DP, Brown LA. Glutathione redox control of asthma: from molecular mechanisms to therapeutic opportunities. Antioxid Redox Signal 2012;17:375-408.

2. Ohwada A, Sato K. Heterogeneity of perception of symptoms in patients with asthma. J Thorac Dis 2019;11:5218-27.

3. Reynaert NL. Glutathione biochemistry in asthma. Biochim Biophys Acta 2011;1810:1045-51.

4. Fitzpatrick AM, Teague WG, Holguin F, et al. Airway glutathione homeostasis is altered in children with severe asthma: evidence for oxidant stress. J Allergy Clin Immunol 2009;123:146-52.e8.

5. Hoshino T, Okamoto M, Takei S, et al. Redoxregulated mechanisms in asthma. Antioxid Redox Signal 2008;10:769-83.

6. Allen J. Inhaled glutathione for the prevention of air pollution-related health effects: a brief review. Altern Ther Health Med 2008;14:42-4.

7. Dut R, Dizdar EA, Birben E, et al. Oxidative stress and its determinants in the airways of children with asthma. Allergy 2008;63:1605-9.

8. Kloek J, Mortaz E, van Ark I, et al. Glutathione prevents the early asthmatic reaction and airway hyperresponsiveness in guinea pigs. J Physiol Pharmacol 2010;61:67-72.

9. Linn WS, Buckley RD, Spier CE, et al. Health effects of ozone exposure in asthmatics. Am Rev Respir Dis 1978;117:835-43.

10. Koike Y, Hisada T, Utsugi M, et al. Glutathione redox regulates airway hyperresponsiveness and airway inflammation in mice. Am J Respir Cell Mol Biol 2007;37:322-9.

11. Casoni GL, Chitano P, Pinamonti S, et al. Reducing agents inhibit the contractile response of isolated guinea-pig main bronchi. Clin Exp Allergy 2003;33:999-1004.

12. Meister A. Glutathione deficiency produced by inhibition of its synthesis, and its reversal; applications in research and therapy. Pharmacol Ther 1991;51:155-94.

13. Wernerman J, Hammarqvist F. Modulation of endogenous glutathione availability. Curr Opin Clin Nutr Metab Care 1999;2:487-92.

14. Martinez-Losa M, Cortijo J, Juan G, et al. Inhibitory effects of $\mathrm{N}$-acetylcysteine on the functional responses of human eosinophils in vitro. Clin Exp Allergy 2007;37:714-22.

15. Prousky J. The treatment of pulmonary diseases and respiratory-related conditions with inhaled (nebulized or aerosolized) glutathione. Evid Based Complement Alternat Med 2008;5:27-35.

16. Anderson ME. Determination of glutathione and glutathione disulfide in biological samples. Methods Enzymol 1985;113:548-55. 
17. Mårtensson J, Meister A. Mitochondrial damage in muscle occurs after marked depletion of glutathione and is prevented by giving glutathione monoester. Proc Natl Acad Sci U S A 1989;86:471-5.

18. Kloek J, Van Ark I, De Clerck F, et al. Modulation of airway hyperresponsiveness by thiols in a murine in vivo model of allergic asthma. Inflamm Res 2003;52:126-31.

19. Kang KW, Lee SJ, Kim SG. Molecular mechanism of nrf2 activation by oxidative stress. Antioxid Redox Signal 2005;7:1664-73.

20. Rangasamy T, Guo J, Mitzner WA, et al. Disruption of Nrf2 enhances susceptibility to severe airway inflammation and asthma in mice. J Exp Med 2005;202:47-59.

21. Witzenrath M, Ahrens B, Kube SM, et al. Detection of allergen-induced airway hyperresponsiveness in isolated mouse lungs. Am J Physiol Lung Cell Mol Physiol 2006;291:L466-72.

22. Gerhold K, Bluemchen K, Franke A, et al. Exposure to endotoxin and allergen in early life and its effect on allergen sensitization in mice. J Allergy Clin Immunol 2003;112:389-96.

23. Hamelmann E, Schwarze J, Takeda K, et al. Noninvasive measurement of airway responsiveness in allergic mice using barometric plethysmography. Am J Respir Crit Care Med 1997;156:766-75.

24. Vandeputte C, Guizon I, Genestie-Denis I, et al. A microtiter plate assay for total glutathione and glutathione disulfide contents in cultured/isolated cells: performance study of a new miniaturized protocol. Cell Biol Toxicol 1994;10:415-21.

25. Akerboom TP, Sies H. Assay of glutathione, glutathione disulfide, and glutathione mixed disulfides in biological samples. Methods Enzymol 1981;77:373-82.

26. Seelig GF, Simondsen RP, Meister A. Reversible dissociation of gamma-glutamylcysteine synthetase into two subunits. J Biol Chem 1984;259:9345-7.

27. Rahman I, Mulier B, Gilmour PS, et al. Oxidant-mediated lung epithelial cell tolerance: the role of intracellular

Cite this article as: Wang Q, Li A, Zheng Y, Zhang S, Wang P. Glutathione ethyl ester supplementation prevents airway hyperresponsiveness in mice. Ann Transl Med 2020;8(22):1519. doi: 10.21037/atm-20-7114 glutathione and nuclear factor-kappaB. Biochem Pharmacol 2001;62:787-94.

28. National Asthma Education and Prevention Program. NAEaP: Expert Panel Report 3 (EPR-3): Guidelines for the Diagnosis and Management of Asthma-Summary Report 2007. J Allergy Clin Immunol 2007;120:S94-138.

29. Biswas SK, Rahman I. Environmental toxicity, redox signaling and lung inflammation: the role of glutathione. Mol Aspects Med 2009;30:60-76.

30. Jeyapaul J, Jaiswal AK. Nrf2 and c-Jun regulation of antioxidant response element (ARE)-mediated expression and induction of gamma-glutamylcysteine synthetase heavy subunit gene. Biochem Pharmacol 2000;59:1433-9.

31. Wild AC, Mulcahy RT. Regulation of gammaglutamylcysteine synthetase subunit gene expression: insights into transcriptional control of antioxidant defenses. Free Radic Res 2000;32:281-301.

32. McMahon M, Itoh K, Yamamoto M, et al. The Cap'n'Collar basic leucine zipper transcription factor $\mathrm{Nrf} 2$ (NF-E2 p45-related factor 2) controls both constitutive and inducible expression of intestinal detoxification and glutathione biosynthetic enzymes. Cancer Res 2001;61:3299-307.

33. Chan K, Han XD, Kan YW. An important function of Nrf2 in combating oxidative stress: detoxification of acetaminophen. Proc Natl Acad Sci U S A 2001;98:4611-6.

34. Wild AC, Moinova HR, Mulcahy RT. Regulation of gamma-glutamylcysteine synthetase subunit gene expression by the transcription factor Nrf2. J Biol Chem 1999;274:33627-36.

35. Yao JW, Liu J, Kong XZ, et al. Induction of activation of the antioxidant response element and stabilization of Nrf2 by 3-(3-pyridylmethylidene)-2-indolinone (PMID) confers protection against oxidative stress-induced cell death. Toxicol Appl Pharmacol 2012;259:227-35.

(English Language Editor: C. Betlazar-Maseh) 